\title{
CORRECTION
}

\section{Correction to: Geometric Over-Constraints Detection: A Survey}

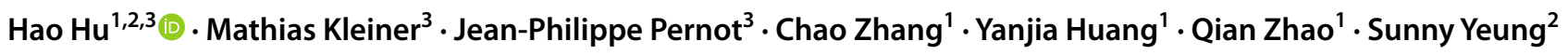

Published online: 2 August 2021

(c) CIMNE, Barcelona, Spain 2021

\section{Correction to: \\ Archives of Computational Methods in Engineering https://doi.org/10.1007/s11831-020-09509-y}

Due to some errors related in initial submission co-authors Jean-Philippe Pernot and Mathias Kleiner were not indicated in the author group and needs to be read as per author group listed above

Original article has been updated.

Publisher's Note Springer Nature remains neutral with regard to jurisdictional claims in published maps and institutional affiliations.

The original article can be found online at https://doi.org/10.1007/ s11831-020-09509-y.

$\mathrm{HaO} \mathrm{Hu}$

huhaoseu@gmail.com

1 Guangdong Bright Dream Robotics, Foshan, China

2 Guangdong Country Garden School, Foshan, China

3 Arts et Métiers Institute of Technology, LISPEN, HESAM

Université, Aix-en-Provence 13617, France 